\title{
Genome
}

\section{Evaluating the efficacy of sample collection approaches and DNA metabarcoding for identifying the diversity of plants utilized by nectivorous bats}

\begin{tabular}{|r|l|}
\hline Journal: & Genome \\
\hline Manuscript ID & gen-2018-0102.R2 \\
\hline Manuscript Type: & Note \\
\hline Author: & 29-Oct-2018 \\
\hline $\begin{aligned} \text { Complete List of Authors: } \\
\text { Keyword: }\end{aligned}$ & $\begin{array}{l}\text { Edwards, Christine; Missouri Botanical Garden, Missouri Botanical } \\
\text { Swift, Joel; Saint Louis University, Biology } \\
\text { Lance, Richard; U.S. Army engineer Research and Revelopment Center, } \\
\text { Environmental Laboratory } \\
\text { Minckley, Thomas; University of Wyoming College of Arts and Sciences, } \\
\text { Department of Geography } \\
\text { Lindsay, Denise; U.S. Army engineer Research and Revelopment Center, } \\
\text { Environmental Laboratory }\end{array}$ \\
\hline $\begin{array}{r}\text { Is the invited manuscript for } \\
\text { consideration in a Special } \\
\text { Issue? : }\end{array}$ & \begin{tabular}{l} 
7th International Barcode of Life \\
\hline
\end{tabular} \\
\hline
\end{tabular}

\section{SCHOLARONE" \\ Manuscripts}


1 Evaluating the efficacy of sample collection approaches and DNA metabarcoding for identifying

2 the diversity of plants utilized by nectivorous bats

4 Christine E. Edwards ${ }^{1}$, Joel F. Swift ${ }^{2}$, Richard F. Lance ${ }^{3}$, Thomas A. Minckley ${ }^{4}$, and Denise L. $5 \quad$ Lindsay $^{3}$

$7 \quad{ }^{1}$ Center for Conservation and Sustainable Development, Missouri Botanical Garden, 4344 Shaw

8 Blvd., St. Louis MO, 63110, USA

$9 \quad{ }^{2}$ Department of Biology, Saint Louis University, 1008 Spring Ave., St. Louis, MO 63110, USA

$10 \quad{ }^{3}$ Environmental Laboratory, US Army Engineer Research and Development Center, 3909 Halls

11 Ferry Rd, Vicksburg, MS, 39180, USA

$12{ }^{4}$ University of Wyoming, Department of Geography and Program in Ecology, 1000 E. University

13 Avenue, Laramie, WY, 82071, USA

14

15 Corresponding Author:

16 Christine.Edwards@mobot.org 


\section{ABSTRACT}

18 In this study, we evaluated the efficacy of sample collection approaches and DNA

19 metabarcoding to identify plants utilized by nectivorous bats. Samples included guano collected

20 from beneath bat roosts and pollen-swabs from bat fur, both of which were subjected to DNA

21 metabarcoding and visual identification of pollen (microscopy) to measure plant diversity. Our

22 objectives were to determine whether DNA metabarcoding could detect likely food plants of

23 nectivorous bats, whether sample types would produce different estimates of plant diversity, and

24 to compare results of DNA metabarcoding to visual identification. Visual identification found

25 that $99 \%$ of pollen was from Agave, which is thought to be the bats' main food source. The

26 dominant taxon found by metabarcoding was also Agavoideae, but a broader diversity of plant

27 species was also detected, many of which are likely "by-catch" from the broader environment.

28 Metabarcoding outcomes differed between sample types, likely because pollen-swabs measured

29 the plant species visited by bats and guano samples measured all items consumed in the bat's

30 diet, even those that were not pollen or nectar. Overall, metabarcoding is a powerful, high-

31 throughput tool to understand bat ecology and species interactions, but careful analysis of results

32 is necessary to derive accurate ecological conclusions.

\section{Key Words}

35 Diet, diversity, DNA metabarcoding, guano, nectivorous bats, plant barcodes, pollen, Agave 


\section{Introduction}

38 Identifying the diversity of food resources used by animals is critical for understanding their

39 behavior, physiological requirements, and habitat needs, all of which are important for effective

40 conservation. Traditionally, techniques to understand the composition and diversity of animal

41 diets have relied on direct behavioral observations and visual identification of feces or gut

42 contents (Bjugstad et al. 1970; Holechek et al. 1982). While providing valuable contributions

43 toward deciphering complex food webs, these techniques are not without limitations (Norbury

44 and Sanson 1992); the feeding behavior of many animal species, particularly those that are

45 nocturnal, is difficult to observe visually, while the visual identification of diet items dissected

46 from fecal samples is painstaking (Ward 1970; Holechek and Gross 1982) and may provide low

47 resolution for identifying the items consumed by an animal. A newer approach to understand

48 animal diet is DNA metabarcoding, which combines high-throughput DNA sequencing, DNA

49 barcodes, and bioinformatic analysis to identify the diversity of species within a sample, even for

50 those diet items that have low representation in fecal droppings (Deagle et al. 2009; Boyer et al.

$512015)$

52 Bats are a group in which visual feeding observations and the identification of the

53 contents of guano (i.e., bat fecal samples) using dissections are particularly limited both in scale

54 and ability to identify the full suite of diet items consumed (Belwood and Fenton 1976; Kunz and

55 Whitaker 1983), particularly for diet items that lack hard remains (e.g., soft-bodied invertebrates;

56 Rabinowitz and Tuttle 1982). For insectivorous bats, knowledge of their diet has been greatly

57 expanded by DNA metabarcoding (Zeale et al. 2011; Vesterinen et al. 2013; Burgar et al. 2014),

58 but the use of metabarcoding has thus far not been well explored for nectivorous bat diet (Voigt

59 et al. 2009). Traditionally, diet analysis of nectivorous bats has relied on microscopic 
60 identification of pollen grains in guano, which requires specialized knowledge of pollen

61 morphology of the regional flora (Voigt et al. 2009). With its speed and potential for greater

62 taxonomic resolution, DNA metabarcoding may be a useful approach to determine the diet of

63 nectivorous bats; however, little is known about the most effective way to conduct DNA

64 metabarcoding studies in nectivorous bats.

65 In this study, we explored the use of DNA metabarcoding to determine the diet of two 66 species of nectivorous bats native to North America, Choeronycteris mexicana (Mexican long-

67 tongued bat; Arroyo-cabrales et al. 1987) and Leptonycteris yerbabuenae (lesser long-nosed bat;

68 Cole and Wilson 2006) in Arizona, USA. Both species are migratory; for example, migratory

69 populations of Leptonycteris yerbabuenae overwinter in Mexico, migrate northward along the

70 coast of Mexico in spring as they follow the blooming of columnar cacti, spend the summer in

71 the southwestern United States where they form maternity colonies, then migrate southward and

72 inland in the fall as they follow the blooming of Agave species (Fleming et al. 1993; Wilkinson

73 and Fleming 1996; Rojas-Martínez et al. 1999; Molina-Freaner and Eguiarte 2003). In the

74 southern part of their range in Mexico, a previous study that conducted visual analysis of guano

75 showed that populations of Leptonycteris yerbabuenae consume pollen and nectar of plants from

76 a diverse range of plants, including species in the families Cactaceae, Bombacaceae, and

77 Agavaceae, among others (Stoner et al. 2003). In addition to pollen and nectar, both species have

78 also been observed to consume cactus fruit as well as insects found on fruit and flowers (Stoner

79 et al. 2003). In Arizona, both species are thought to forage primarily on Agave during the

80 maternity season, but to our knowledge, no comprehensive investigation of nectivorous bat food

81 resources has been conducted on these two species in Arizona. 
We collected guano samples and pollen-swabs of the fur of two species of nectivorous

83 bats and subjected them to both visual analysis of pollen and DNA metabarcoding. Our objectives were to determine whether DNA metabarcoding could detect likely food plant species

85 of nectivorous bats, whether the two types of samples would produce different estimates of plant

86 diversity, and how estimates of plant diversity using DNA metabarcoding would compare to

87 visual identification of pollen isolated from the same samples. Ultimately, this research was

88 designed to understand whether DNA metabarcoding would provide more rapid, refined, and

89 information-rich capabilities for determining trophic interactions, foraging sites, and other

90 related ecological dynamics of bats, whose behavior and diet are challenging to study using

91 conventional techniques.

\section{Materials and Methods}

\section{Sample Collection}

95 We obtained all necessary state and federal permits and ethics approvals prior to conducting

96 research. We collected two sample types, guano and pollen-swabs, from C. mexicana and $L$.

97 yerbabuenae throughout southeastern Arizona. Sample collection focused on the region of

98 southeastern Arizona where there are large L. yerbabuenae maternity roosts and many plant

99 species with bat pollination syndromes (including Agave -- A. chrysantha, A. palmeri, and A.

100 parryi) that flower during and following the mid-summer monsoons, making it a prime foraging

101 location for nectivorous bats. Guano was collected by placing new plastic sheeting attached to

102 PVC pipe frames beneath the primary flight corridor of a large L. yerbabuenae maternity roost,

103 Pyeatt Cave, and beneath a night roost, Wren Bridge, used by both C. mexicana and L.

104 yerbabuenae (Fig 1A \& B). Small numbers of C. mexicana may also occur in Pyeatt Cave. The 
105 guano of nectivorous bats is dropped as a "splat". We obtained 130 "splat" samples from these

106 sites during four collection periods, totaling ten days, in August and September of 2009 and

107 2010. We collected the splat samples using sterile wooden sticks to scrape the material from the

108 sheeting surface into sterile $2.0 \mathrm{~mL}$ screw-cap tubes filled with Invitrogen ${ }^{\mathrm{TM}} \mathrm{RNA}$ later ${ }^{\mathrm{TM}}$

109 Stabilization Solution (ThermoFisher Scientific; Fig 1C \& D). The wooden sticks were cut off

110 into the tube before capping to retain as much guano as possible prior to DNA extraction.

111 Because roosts contained both species of nectivorous bats, the identity of bat species that

112 produced a guano sample was unknown.

113 Pollen-swab samples were collected from 152 C. mexicana and L. yerbabuenae captured

114 by bat experts at sites throughout southeastern Arizona between August and November of 2010

115 and 2011. Capture and handling protocol followed the guidelines of the American Society of

116 Mammalogists (Sikes et al. 2011). Collections were made individually using a new, sterile

117 Catch-All ${ }^{\mathrm{TM}}$ Sample Collection Swab (Epicentre) moistened with RNAlater ${ }^{\mathrm{TM}}$ Stabilization

118 Solution and swiped across each bat's muzzle and shoulders (whether pollen was visible or not;

119 Fig 1E \& F). Swab tips were then clipped off into a sterile, DNA-free $2.0 \mathrm{~mL}$ screw-cap tube

120 filled with RNAlater ${ }^{\mathrm{TM}}$.

121 Guano and Pollen-Swab Sample Grouping and Visual Identification of Pollen

122 Because many samples contained only a small amount of pollen, we pooled samples that

123 were of the same type (guano or pollen-swab), location (nearest town or bridge/cave), and date

124 of sampling. For the pollen-swab samples, we also divided the samples by species $(L$.

125 yerbabuenae or C. mexicana), which was unknown for guano samples. Although we collected a

126 similar number of total samples using the two approaches, because the number of samples that

127 could be collected each night varied, the number of pooled sample groups and number of 
128 samples within each group varied. For guano samples, a larger number of samples could often be

129 collected in a single night, but the bat species corresponding to each fecal sample was unknown,

130 resulting in a total of 5 pooled samples, each containing between 2 and 40 individual guano

131 samples. For pollen-swab samples, because fewer samples could be collected per night and the

132 bat species was known, the samples were divided into a greater number of pooled samples,

133 resulting in 43 pooled pollen-swab samples, each containing samples from between 1 and 14

134 individual bats (Table 1).

135 We identified four pooled guano samples and four pooled pollen-swab samples for

136 quantification of plant diversity by direct visual identification of pollen using light microscopy.

137 For these pooled samples, half was removed for visual analysis and the other half was reserved

138 for DNA extraction and metabarcoding (see below). The pooled guano samples analyzed by

139 visual analysis were samples $1,2,4$, and 5 and the pooled pollen-swab samples were $6,12,13$,

140 and 23. Visual analysis of pollen composition was conducted at the University of Wyoming, with

141 all samples undergoing acetolysis following the standard protocol in Faegri et al. 1989. Samples

142 were initially centrifuged to concentrate pollen in the RNAlater ${ }^{\mathrm{TM}}$ Stabilization Solution to

143 estimate total pollen volume (to the nearest fraction of a milliliter). A single Lycopodium tablet

144 with known concentration (average $=12,542$; University of Lund batch number 124961) was

145 added to each sample $(\mathrm{N}=10)$ as a standard of known concentration against which pollen in the

146 samples can be compared to determine total pollen concentration per sample. Lycopodium spores

147 were encased in a bicarbonate matrix, dissolved with the addition of $1 \mathrm{~mL}$ of $10 \%$ hydrochloric

148 acid (which also broke down the matrix of RNAlater ${ }^{\mathrm{TM}}$ ), allowing for the continuation of

149 standard pollen acetolization (Faegri et al. 1989). No further treatment of these samples was

150 required for proper identification of the pollen grains. Samples were counted to a standard sum 
151 of 300 pollen grains or 1000 Lycopodium spores. These count values balance the need for a

152 statistically complete evaluation of pollen diversity in each sample (Maher 1963) and provide a

153 reasonable assessment of samples with little to no pollen.

154 DNA Extraction, Metabarcoding, and Sequencing

155 DNA was extracted from each guano $(\mathrm{N}=130)$ and pollen-swab $(\mathrm{N}=152)$ sample individually

156 using a modified CTAB extraction protocol (Doyle and Doyle 1987; Lalhmangaihi et al. 2015).

157 Genomic DNA concentrations $(\mathrm{ng} / \mu \mathrm{l})$ were determined with the NanoDrop® ND-1000 UV-Vis

158 Spectrophotometer (Nanodrop Technologies), then equimolar concentrations were pooled as

159 listed in Table 1.

160 Library preparation followed the 454 Sequencing System Guidelines for Amplicon

161 Experimental Design (Roche 2011). We employed three plant chloroplast DNA barcode regions,

$162 r b c L, p s b A-t r n H$, and $t r n L-F$ (Table S1). To enable pooling of the libraries for all samples in a

163 single 454 run, we ordered a unique set of the three plant chloroplast primers for each sample

164 that were tagged with a sample-specific multiple identifier (MID); the MIDs (1-47; Roche 2009)

165 assigned to each were the same as the pooled sample names as shown in Table 1. To enable

166 sequencing on a Roche 454 GS FLX DNA sequencer, the 5' end of each forward and reverse

167 PCR primer was tagged with the A and B 454 adapter (A:

168 CGTATCGCCTCCCTCGCGCCATCAG, B: CTATGCGCCTTGCCAGCCCGCTCAG),

169 respectively. PCR reactions were conducted in $25 \mathrm{uL}$ volumes consisting of $2 \mathrm{U}$ of Platinum Taq

170 DNA polymerase (Invitrogen), 1× Taq DNA Polymerase PCR Buffer without magnesium

171 [containing Tris $\mathrm{HCl}(\mathrm{pH} 8.4)$, and $\mathrm{KCl}$ ], $2.0 \mathrm{mM} \mathrm{MgCl}_{2}, 0.2 \mathrm{mM}$ of each dNTP, $1 \mu \mathrm{M}$ of both

172 forward and reverse primers, and nuclease-free water. PCR temperature cycling conditions were

173 as follows: (I) $3 \mathrm{~min}$ at $95^{\circ} \mathrm{C}$, (II) denaturation for $30 \mathrm{~s}$ at $95^{\circ} \mathrm{C}$, (III) annealing for $30 \mathrm{~s}$ at 55 
$174{ }^{\circ} \mathrm{C}$, (IV) extension for $30 \mathrm{~s}$ at $72{ }^{\circ} \mathrm{C}$, (V) eight repetitions of steps $2-4$, and (VI) a final

175 elongation at $72{ }^{\circ} \mathrm{C}$ for $5 \mathrm{~min}$. PCR products were quantified, pooled in equimolar ratios, and

176 submitted for next-generation DNA sequencing using a 1/4-plate run with on a Roche $454 \mathrm{GS}$

177 FLX DNA sequencer using titanium chemistry at the University of Florida's Interdisciplinary

178 Center for Biotechnology Research.

179 Bioinformatic Analysis

180 The resulting reads were first processed using the 454 amplicon processing pipeline. The

181 resulting file was demultiplexed by MID and quality filtered using split_libraries.py (QIIME

182 V1.91; Caporaso et al., 2010) with the following settings; minimum sequence length of 170

183 nucleotides, maximum homopolymer size of 8 , mean quality score above 25 and allowing for up

184 to 2 primer mismatches. Chimeric sequence filtering was performed on each primer separately

185 using identify_chimeric_seqs.py and filter_fasta.py (QIIME) with the implemented USEARCH

186 de novo algorithm using default settings (Edgar 2010). Taxonomic assignment of sequences was

187 conducted using BLASTN (blastn-2.2.31+; Camacho et al. 2009), with local alignments of query

188 sequences to the NCBI nt database (downloaded 08/25/2017; NCBI Resource Coordinators

189 2017). BLAST searches were run in parallel using GNU parallel (Tange 2011), with a word size

190 of 11 and an E-value cutoff of 1E-10. Taxonomic binning was performed on the top $10 \%$ of

191 BLAST hits to a query sequence by bit score using Megan6 CE v6.11.4 with the naive lowest

192 common ancestor algorithm (Huson et al. 2016) with default settings, except we used a percent

193 identity cutoff of $92 \%$. Megan filters hits by e-values and percent identity and summarizes the

194 taxonomic hits to a query, finding the "lowest common ancestor," or lowest taxonomic rank

195 common to the hits, such that each read has only one assignment at the most appropriate

196 taxonomic rank. Because we obtained relatively few annotated sequences for some samples, to 
197 maximize the data and number of samples analyzed, we did not filter out singletons.

198 Furthermore, because we obtained relatively few sequences for two of the three markers, we

199 summarized the results using a "total evidence" approach, combining all of the annotations

200 across all markers, such that each annotation, regardless of marker, was treated as a separate

201 identification. To determine whether the results generated using the three types of analysis

202 differed significantly, we used a chi-squared test to analyze whether the relative proportions of

203 Agavoideae vs. other types of taxa were similar between each pair of approaches.

\section{Results}

\section{Visual Identification of Pollen}

207 For the visual identification, the mean proportion of Agave in the observed pollen from both the 208 guano and pollen-swab samples was $99.6 \%$. In half of the samples, Agave pollen was the only

209 type identified. The second most common pollen type identified was the Yucca type according to 210 the keys used. However, the keys require mature pollen, and it is possible that some percentage

211 of Agave pollen may have been immature; it is therefore possible that pollen grains identified to

212 Yucca may have been immature Agavaceae pollen, as the morphologies of these types are fairly

213 similar. Only three other pollen types were identified, including an Anacardiaceae grain (Group

214 1), Ambrosia-type (Group 2), and Malvaceae (Group 6).

\section{DNA Metabarcoding of Pollen}

216 We obtained 60,662 total DNA sequences with amplicon length $>170 \mathrm{bp}$, of which 42,950 were

$217 \operatorname{trn} L-F, 14,265$ were $p s b A-\operatorname{trn} H$, and 3,447 were $r b c L$. The mean and median length of these

218 sequences was $349 \mathrm{bp}$ and $322 \mathrm{bp}$, respectively, which corresponds closely with the expected

219 sizes of trnL-F and $p s b A-t r n H$. Because we recovered relatively small numbers of sequences for 
220 both $r b c L$ and $p s b A-t r n H$, the three primers from each sample were combined and analyzed

221 together. When all markers were combined, 52,409 sequences (86\%) were from the guano

222 samples and 8,253 (14\%) were from the pollen-swab samples. After annotating

223 and filtering the annotations, across all samples, a total of 15,074 sequences were annotated to

22485 plant taxa. Plant DNA sequences were recovered from four of the five pooled guano samples

225 and 19 of the 43 pooled pollen-swab samples (Table 1). A total of 8,662 sequences were

226 annotated to plants from the guano samples and 6,412 were annotated to plants from the pollen-

227 swab samples. The number of sequences annotated to plants per group ranged from 620 to 3,354

228 for the guano samples and from 1 to 1,912 for the pollen-swab samples. Across all samples, the

229 majority of sequences $(8,889)$ were assigned to Agave, Yucca, and other taxa in Agavoideae,

230 which were all combined in figures under "Agavoideae" (Fig. 2).

231 When the metabarcoding results for all guano samples were combined into one analysis

232 (Fig 2a), 32.6\% of the sequences were from Agavoideae, $40.8 \%$ were from the genus Wolffia,

$2337 \%$ were from the order Zingiberales, $5.7 \%$ was from the genus Musa, 3.2\% were from the

234 subclass Petrosaviidae (which contains the order Asparagales), 2.9\% were from the

235 Cupressaceae family, $1.8 \%$ were from Lemnoideae, $1 \%$ were from the genus Pisium, and a

236 number of other taxa were recovered at lower sequence depths (i.e., $<1 \%$ of the total sequences

237 recovered from guano), which are combined in the category "other angiosperms" in Fig. 2. The

238 chi-square test comparing the results of visual identification of pollen to those of metabarcoding

239 of fecal samples showed that the relative proportions of Agavaoideae vs. other taxa differed

240 significantly $\left(\chi^{2}=97.0588, p<.00001\right)$. When the guano samples were each analyzed

241 individually, Agavoideae was the main DNA sequence type for two of four guano samples (Fig 
242 2c). The third guano sample was made up primarily of DNA sequences of Wolffia, while the

243 fourth guano group was composed of roughly equal proportions of sequences from Musa and

244 Zingiberales (Fig 2c).

245 For the metabarcoding of pollen-swab samples, when the read counts were summed

246 across all samples (Fig. 2b), we obtained a total of 6,412 sequences annotated to plants, $93.6 \%$ of

247 which were Agavoideae (Fig. 2b), with all other taxa recovered at frequencies lower than $1 \%$.

248 Agavoideae was the main DNA sequence type found in 17 of the 19 pollen-swab samples (Fig.

249 2c). The second most common group was the "other angiosperms" group, which is comprised of

250 all of the taxa found at frequencies $<1 \%$. Two samples were dominated by "other angiosperms",

251 but both of these samples produced very few sequences (i.e., $<10$ sequences per sample). The

252 relative proportions of Agavaoideae vs. other taxa found by metabarcoding of pollen-swab

253 samples did not differ significantly from those found through visual identification of pollen $\left(\chi^{2}=\right.$

254 3.701. $p=0.054)$, but they differed significantly with those obtained from metabarcoding of fecal

255 samples $\left(\chi^{2}=80.2718, p<.00001\right)$.

\section{Discussion}

257 In this study, the first objective was to determine whether DNA metabarcoding could detect

258 likely foods utilized by nectivorous bats. DNA metabarcoding successfully identified plant DNA

259 sequences from both guano and pollen-swab samples, and the majority of sequences recovered

260 were from Agavoideae, which corresponds to the most common food source utilized by

261 nectivorous bats in this region based on behavioral observations. These dominant species

262 recovered by metabarcoding also corresponds to that found using morphological identification of

263 the pollen in the samples, which found that $99.6 \%$ of pollen from C. mexicana and $L$.

264 yerbabuenae guano and pollen-swab samples was Agave. These results suggest that 
metabarcoding analysis of both pollen-swab and guano samples is able to detect the main food 266 source utilized by nectivorous bats.

268 sequences from a diverse range of plant species in the samples, indicating that metabarcoding is 269 a very sensitive approach to determine the plants with which nectivorous bats interact. Some of 270 these taxa may be utilized as food sources by bats; for example, we detected sequences of taxa in 271 the genus Musa and the order Zingiberales, many of which have been shown to be visited by 272 nectar bats in other regions (Liu et al. 2002; Fleming et al. 2009; Pedrozo et al. 2018). Although 273 neither of these groups is native to the study area, both are commonly cultivated for food or as 274 ornamental plants and could be utilized occasionally by bats as a food source.

275 Many of the additional plant species found in the metabarcoding results are not bat276 pollinated and are unlikely to be utilized by bats as food resources; instead, they may occur in the 277 sample from incidental transfer or pollen by-catch from the broader network of species 278 interactions within the community. For example, metabarcoding of guano samples found that 279 many sequences in two guano samples matched with high similarity to the small, freshwater, 280 aquatic taxa Wolffia and Lemnoideae (Araceae). Although Wollfia are not present in the region, 281 multiple species of two closely related genera in the Lemnoideae subfamily, Lemna and 282 Spirodela, are present. These could have arisen in the sample through incidental transfer from 283 bats drinking water from freshwater ponds, and indeed, these plants are thought to be dispersed 284 by animals transporting vegetative tissue and seeds (Keddy 1976). In addition, metabarcoding of 285 one guano sample showed a large proportion of sequences from the Cupressaceae, which are 286 wind-pollinated and unlikely to be a food source for bats. Given that Pinyon-juniper forests are 287 common in the region, Juniperus pollen may have been deposited by the wind onto collecting 
surfaces, into the nectary wells or the stigma of the flowers visited by the bats, or onto the bats

289 themselves and then consumed through grooming. Other small numbers of sequences may have

290 arisen in the sample by incidental transfer from the broader network of species interactions

291 within the plant-pollinator community.

The other goals of the study were to determine whether the two types of samples would

293 produce different estimates of plant diversity, and how estimates of plant diversity using DNA

294 metabarcoding would compare to visual identification of pollen isolated from the same samples.

295 Although the results of visual analysis of both types of samples and metabarcoding of pollen-

296 swab samples were highly similar, the results of metabarcoding of guano samples differed

297 dramatically. Visual identification of pollen in both sample types found that 99\% was

298 Agavoideae, and results of metabarcoding of pollen-swab samples showed a comparable

299 proportion of sequences from Agavoideae (93.6\%). In contrast, results of metabarcoding of

300 guano samples were significantly different from visual analysis, showing fewer sequences from

301 the Agavoideae (32.6\%), and a greater number from taxa such Wolffia (40.8\%), Zingiberales

302 (7\%), Musa (5.7\%), etc. However, despite the proportions of reads differing across the different

303 types of analysis, it should be noted that Agavoideae sequences were consistently recovered in

304 almost all samples for each of the three types of analysis, indicating that it is an important

305 component of the diet of these bats.

These differences in the estimates of diversity among the types of samples and analyses

307 are likely because they are measuring slightly different things. Visual identification of pollen in

308 both types of samples measured only pollen, whereas metabarcoding measures any type of DNA

309 present in the sample. Results of metabarcoding of the pollen-swab samples were more similar to

310 visual analysis, likely because the sample was composed primarily of pollen and contained very 
311 little other plant DNA. Metabarcoding of guano samples demonstrated larger differences relative

312 to the results of visual analysis, likely because the samples may contain anything consumed by

313 the bats, including pollen, nectar, or any other items such as fruit, leaf tissue, or insects. Because

314 we used chloroplast genes for metabarcoding, if the bats consumed foods such as fruit (i.e.,

315 Musa, or bananas) or leaf tissue (i.e., the small freshwater aquatic plants such as Wolffia or

316 Lemnoideae) that have higher densities of chloroplasts than pollen/nectar, these items may be

317 disproportionately represented in metabarcoding results. Because relative proportions of

318 sequences per diet item in our study may be biased according to the type of tissue consumed,

319 data from guano samples should therefore not be used to determine the relative abundance of

320 food items in the diet. Overall, these results indicate that sample collection techniques could be

321 tailored depending on the question, with pollen-swab samples used to understand what plant

322 species the bats are visiting and guano samples used to understand other potential aspects of bat

323 diet and ecology.

324 It is also worth noting that the efficiency and ease of collecting and working with the two

325 types of samples differed. Collecting pollen-swab samples involved capturing the bats to remove

326 the pollen from their muzzles, requiring significant animal-handling expertise and potentially

327 causing stress to the bats; however, this also enabled visual identification of the species of bat

328 from which the sample originated, thereby increasing resolution. Pollen-swab samples were also

329 generally very small in volume, contained very little DNA, and produced relatively few

330 sequences per sample; however, this may partially have been an artifact of the smaller average

331 number of individual samples pooled together for pollen-swab samples (Table 1). The data

332 produced by pollen-swab samples were generally of higher quality, as most of the sequences

333 produced from pollen-swab samples were annotated to plants. In contrast, guano samples were 
334 much easier to collect, as it simply required collecting guano samples from plastic sheeting

335 placed under roots or flyways, which caused little to no disturbance or stress to the bats. One

336 drawback of guano samples is that we were unable to visually determine the species of bat

337 associated with each sample; however, if each fecal sample is analyzed individually, then DNA

338 sequencing of loci to distinguish bat species could be employed to obtain this information (Swift

339 et al. 2018). Guano samples generally were also of larger volume, produced a greater quantity of

340 DNA, and provided more sequences per sample than pollen-swab samples; however, only a

341 small proportion (17\%) of the 52,409 DNA sequences were annotated to plants, with the

342 remaining sequences annotated to bacteria, fungi, and a large proportion of sequences not able to

343 be annotated. The guano samples also may have contained a variety of tissue types, which may

344 have biased the relative proportion of sequences recovered for the diet items. These relative

345 strengths and drawbacks should be considered carefully when choosing sampling strategies for

346 future studies.

347 Strengths of DNA metabarcoding include the ability to process more samples, faster, than

348 visual identification of pollen. It is more sensitive than visual identification of pollen and able to

349 recover information about diversity from unidentifiable samples (i.e., digested fruit pulp or leaf

350 tissue in fecal samples). Although metabarcoding detected a wider range of taxa in the present

351 study than visual analysis, one limitation of metabarcoding is that its power to detect taxa may be

352 limited somewhat by low taxonomic resolution; for example, many taxa were identified only to

353 the level of subfamily or family and this low resolution could have led to some false positives

354 and could explain some of the unexpected taxa detected in this study. The low taxonomic

355 resolution observed in the metabarcoding data may be the result of issues with plant DNA

356 barcodes, which frequently have low levels of variability and often lack the power to resolve 
357 DNA sequences to the species level (Fahner et al. 2016; Hollingsworth et al. 2016). Low

358 taxonomic resolution in metabarcoding may also arise from problems related to DNA sequence

359 databases, such as low accuracy of species identifications or poor representation of the taxa of a

360 region; however, this was less likely to be a factor affecting our study, as the plant species in this

361 region are generally well represented in NCBI. Low taxonomic resolution, however, is not

362 unique to metabarcoding, as visual analysis of pollen is similarly limited in its ability to provide

363 taxonomic resolution for many taxa.

364 In contrast to visual analysis, which provides a quantitative estimate of the relative

365 proportion of different types of pollen in a sample, another weakness of DNA metabarcoding is

366 that it may not provide an accurate estimate of relative abundance of items in the diet. Previous

367 studies have shown that the proportion of sequence reads corresponded only weakly to the

368 relative abundance of items in samples of known composition (Bell et al. 2018). Similarly, we

369 found a great deal of variability in the relative proportions of diet items recovered among the

370 different approaches used in the study, suggesting that at least some of them do not accurately

371 reflect the relative abundance of diet items.

$372 \quad$ For future studies, we would recommend employing individual-level samples in analyses

373 and making use of DNA sequencing technologies that produce a greater number of sequences

374 (i.e., Illumina MiSeq), as this will provide even greater resolution of nectivorous bat diet. To

375 detect potential contamination that may be introduced during sample collection (e.g., wind-borne

376 pollen or plant debris that may contaminate samples when collecting guano from plastic

377 sheeting) or during laboratory processing, we recommend that future studies follow the sample

378 processing protocols and negative controls outlined in detail in Swift et al. (2018). To ensure

379 good identification and coverage of regional taxa in DNA sequence databases, we also 
recommend that researchers simply develop DNA barcoding databases of the potential taxa in

381 their samples. Finally, given that many of the plant species identified by DNA metabarcoding in

382 this study were not likely utilized as food resources by bats and instead may result from

383 incidental transfer or pollen by-catch, we emphasize that careful analysis and interpretation of

384 results is necessary to derive accurate and robust ecological conclusions. Overall, the results of

385 this study indicate that metabarcoding, particularly of fecal samples, is a rapid, high-throughput, 386 and efficient approach to understand nectivorous the diet and species interactions of nectivorous 387 bats.

389 Data availability

390 Raw sequencing data can be downloaded from both

391 https://github.com/Kenizzer/Nectar_bat_metabarcoding and the NCBI Sequence Read Archive

392 under BioProject ID PRJNA492812. Instructions and code for sequence processing and data 393 analysis is provided at https://github.com/Kenizzer/Nectar_bat_metabarcoding.

\section{Acknowledgements}

396 We are grateful to Sheridan Stone for assistance with permitting and access to bat populations,

397 Ronnie Sidner, Eric Britzke, Scott Richardson, and Shawn Lowery for their assistance in

398 collecting pollen samples from captured bats, George Ferguson and Pamela Bailey for their

399 assistance in collecting potential food plants from southeastern Arizona, and Zachary N. Harris

400 for helpful input on bioinformatics analyses. Laboratory assistance was provided by Michael

401 Jung and Xin Guan. We thank Sarah Adamowicz, Xin Zhou, and two anonymous reviewers for 402 comments on a previous draft of this manuscript. 
Funding for this project was provided by the U.S. Army's 6.1 Basic Research Program.

404 Permission was granted by the Chief of Engineers to publish this information. The views

405 expressed in this manuscript are those of the authors and do not reflect the official policy or

406 position of the Department of the Army, Department of Defense, or the U.S. Government.

\section{References}

410 Arroyo-cabrales, J., Hollander, R.R., and Jones, J.K. 1987. Choeronycteris mexicana. Mamm.

411 Biol. (291): 1-5. doi:10.2307/3503823.

412 Bell, K.L., Burgess, K.S., Botsch, J.C., Dobbs, E.K., Read, T.D., and Brosi, B.J. 2018.

413 Quantitative and qualitative assessment of pollen DNA metabarcoding using constructed $414 \quad$ species mixtures. Mol. Ecol. doi:10.1111/mec.14840.

415 Belwood, J.J., and Fenton, M.B. 1976. Variation in the diet of Myotis lucifugus (Chiroptera:

416 Vespertilionidae). Can. J. Zool. 54(10): 1674-1678. doi:10.1139/z76-194.

417 Bjugstad, A.J., Crawford, H.S., and Neal, D.L. 1970. Determining forage consumption by direct 418 observation of domestic grazing animals. In Range and Wildlife Habitat Evaluation. US 419 Forest Service Miscellaneous Publications, Washington, D.C. pp. 101-104.

420 Boyer, S., Cruickshank, R.H., and Wratten, S.D. 2015. Faeces of generalist predators as

Burgar, J.M., Murray, D.C., Craig, M.D., Haile, J., Houston, J., Stokes, V., and Bunce, M. 2014. "biodiversity capsules": A new tool for biodiversity assessment in remote and inaccessible Who's for dinner? High-throughput sequencing reveals bat dietary differentiation in a biodiversity hotspot where prey taxonomy is largely undescribed. Mol. Ecol. 23(15): 3605- 
3617. doi:10.1111/mec. 12531 .

427

428

429

430

431

432

433

434

435

436

437

438

439

440

441

442

443

444

445

446

447

448

Camacho, C., Coulouris, G., Avagyan, V., Ma, N., Papadopoulos, J., Bealer, K., and Madden, T.L. 2009. BLAST+: architecture and applications. BMC Bioinformatics 10(1): 421. doi:10.1186/1471-2105-10-421.

Caporaso, J.G., Kuczynski, J., Stombaugh, J., Bittinger, K., Bushman, F.D., Costello, E.K., Fierer, N., Peña, A.G., Goodrich, J.K., Gordon, J.I., Huttley, G.A., Kelley, S.T., Knights, D., Koenig, J.E., Ley, R.E., Lozupone, C.A., Mcdonald, D., Muegge, B.D., Pirrung, M., Reeder, J., Sevinsky, J.R., Turnbaugh, P.J., Walters, W.A., Widmann, J., Yatsunenko, T., Zaneveld, J., and Knight, R. 2010. QIIME allows analysis of high- throughput community sequencing data Intensity normalization improves color calling in SOLiD sequencing. Nat. Methods 7(5): 335-336. doi:10.1038/nmeth0510-335.

Cole, F.R., and Wilson, D.E. 2006. Leptonycteris yerbabuenae. Mamm. Species (797): 1-7. doi:10.1644/797.1.

Coordinators, N.R. 2017. Database Resources of the National Center for Biotechnology Information. Nucleic Acids Res. 45(D1): D12-D17. doi:10.1093/nar/gkw1071.

Deagle, B.E., Kirkwood, R., and Jarman, S.N. 2009. Analysis of Australian fur seal diet by pyrosequencing prey DNA in faeces. Mol. Ecol. 18(9): 2022-2038. doi:10.1111/j.1365294X.2009.04158.x.

Doyle, J., and Doyle, J. 1987. A rapid isolation procedure for small quantities of fresh tissue. Phytochem. Bull. 19: 11-15.

Edgar, R.C. 2010. Search and clustering orders of magnitude faster than BLAST. Bioinformatics 26(19): 2460-2461. doi:10.1093/bioinformatics/btq461.

Faegri, K., Kaland, P.E., and Kzywinski, K. 1989. Textbook of Pollen Analysis. 4th edition. 
Wiley, New York.

450

451

452

453

454

455

456

457

458

459

460

461

462

463

464

465

466

467

468

469

470

471

Fahner, N.A., Shokralla, S., Baird, D.J., and Hajibabaei, M. 2016. Large-Scale Monitoring of Plants through Environmental DNA Metabarcoding of Soil: Recovery, Resolution, and Annotation of Four DNA Markers. PLoS One 11(6): e0157505. doi:10.1371/journal.pone.0157505.

Fay, M.F., Swensen, S.M., and Chase, M.W. 1997. Taxonomic Affinities of Medusagyne oppositifolia (Medusagynaceae). Kew Bull. 52(1): 111-120. doi:10.2307/4117844.

Fleming, T.H., Geiselman, C., and Kress, W.J. 2009. The evolution of bat pollination: A phylogenetic perspective. Ann. Bot. 104(6): 1017-1043. doi:10.1093/aob/mcp197.

Fleming, T.H., Nuñez, R.A., and Sternberg, L. da S.L. 1993. Seasonal changes in the diets of migrant and non-migrant nectarivorous bats as revealed by carbon stable isotope analysis. Oecologia 94(1): 72-75. doi:10.1007/BF00317304.

Holechek, J.L., and Gross, B. 1982. Training Needed for Quantifying Simulated Diets from Fragmented Range Plants. J. Range Manag. 35(5): 644-647. doi:10.2307/3898655.

Holechek, J.L., Vavra, M., Pieper, R.D., Journal, S., May, N., Holechek, J.L., Vavra, M., and Pieper, R.E.X.D. 1982. Botanical Composition Determination of Range Herbivore Diets : A Review. J. Range Manag. 35(3): 309-315.

Hollingsworth, P.M., Li, D.-Z., van der Bank, M., and Twyford, A.D. 2016. Telling plant species apart with DNA: from barcodes to genomes. Philos. Trans. R. Soc. B Biol. Sci. 371(1702): 20150338. doi:10.1098/rstb.2015.0338.

Huson, D.H., Beier, S., Flade, I., Górska, A., El-Hadidi, M., Mitra, S., Ruscheweyh, H.-J., and Tappu, R. 2016. MEGAN Community Edition - Interactive Exploration and Analysis of Large-Scale Microbiome Sequencing Data. PLOS Comput. Biol. 12(6): e1004957. 
472

473

474

475

476

477

478

479

480

481

482

483

484

485

486

487

488

489

490

491

492

493

494

doi:10.1371/journal.pcbi.1004957.

Keddy, P.L. 1976. Lakes as islands: the distributional ecology of two aquatic plants, Lemna minor L. and L. trisulca L. Ecology 57(2): 353-359.

Kress, W.J., Wurdack, K.J., Zimmer, E.A., Weigt, L.A., and Janzen, D.H. 2005. Use of DNA barcodes to identify flowering plants. Proc. Natl. Acad. Sci. 102(23): 8369-8374. doi:10.1073/pnas.0503123102.

Kunz, T.H., and Whitaker, J.O.J. 1983. An evaluation of fecal analysis for determining food habits of insectivorous bats. Can. J. Zool. 61(6): 1317-1321.

Lalhmangaihi, R., Ghatak, S., Laha, R., Gurusubramanian, G., and Kumar, N.S. 2015. Protocol for Optimal Quality and Quantity Pollen DNA Isolation from Honey Samples. J. Biomol. Tech. 25(4): 92-95. doi:10.7171/jbt.14-2504-001.

Liu, A., Li, D., Wang, H., and Kress, W.J. 2002. Ornithophilous and Chiropterophilous Pollination in Musa itinerans ( Musaceae ), a Pioneer Species in Tropical Rain Forests of Yunnan, Southwestern China. Biotropica 34(2): 254-260.

Maher, L.J. 1963. Pollen Analyses of Surface Materials from the Southern San Juan Mountains, Colorado. Geol. Soc. Am. Bull. 74(12): 1485-1503.

Molina-Freaner, F., and Eguiarte, L.E. 2003. The pollination biology of two paniculate agaves (Agavaceae) from Northwestern Mexico: contrasting roles of bats as pollinators. Am. J. Bot. 90(7): 1016-1024.

Norbury, G.L., and Sanson, G.D. 1992. Problems with measuring diet selection of terrestrial, mammalian herbivores. Aust. J. Ecol. 17(1): 1-7. doi:10.1111/j.1442-9993.1992.tb00774.x.

Pedrozo, A.R., Gomes, L.A.C., and Uieda, W. 2018. Feeding behavior and activity period of three Neotropical bat species (Chiroptera: Phyllostomidae) on Musa paradisiaca 
inflorescences (Zingiberales: Musaceae). Iheringia. Série Zool. 108: 1-8. doi:10.1590/1678$4766 \mathrm{e} 2018022$.

497 Rabinowitz, A., and Tuttle, M.D. 1982. A test of the validity of two currently used methods of 498 determining bat prey preferences. Acta Theriol. 27(21): 13-24.

Rojas-Martínez, A., Valiente-Banuet, A., del Coro Arizmendi, M., Alcántara-Eguren, A., and Arita, H.T. 1999. Seasonal distribution of the long-nosed bat (Leptonycteris curasoae) in North America: does a generalized migration pattern really exist? J. Biogeogr. 26(5): 1065-

Sang, T., Crawford, D.J., and Stuessy, T.F. 1997. Chloroplast DNA phylogeny, reticulate evolution, and biogeography of Paeonia (Paeoniaceae). Am. J. Bot. 84(8): 1120-1136.

Sikes, R.S., Gannon, W.L., and The Animal Care and Use Commitee of the American Society Mammalogists 2011. Guidelines of the American Society of Mammalogists for the use of

Stoner, K.E., O.-Salazar, K.A., R.-Ferdandez, R.C., and Quesada, M. 2003. Population wild mammals in research and education: J. Mammal. 92(1): 235-253. doi:10.1093/jmammal/gyw078.

514 Swift, J.F., Lance, R.F., Guan, X., Britzke, E.R., Lindsay, D.L., and Edwards, C.E. 2018.

515 Multifaceted DNA metabarcoding: Validation of a noninvasive, next-generation approach to studying bat populations. Evol. Appl. 11(7): 1120-1138. doi:10.1111/eva.12644.

517 Taberlet, P., Coissac, E., Pompanon, F., Gielly, L., Miquel, C., Valentini, A., Vermat, T., 
Corthier, G., Brochmann, C., and Willerslev, E. 2007. Power and limitations of the chloroplast trnL (UAA) intron for plant DNA barcoding. Nucleic Acids Res. 35(3). doi:10.1093/nar/gk1938.

521 Tange, O. 2011. GNU Parallel: the command-line power tool. ;login USENIX Mag. 36(1): 4247. doi:10.5281/zenodo.16303.

Vesterinen, E.J., Lilley, T., Laine, V.N., and Wahlberg, N. 2013. Next Generation Sequencing of Fecal DNA Reveals the Dietary Diversity of the Widespread Insectivorous Predator Daubenton's Bat (Myotis daubentonii) in Southwestern Finland. PLoS One 8(11): e82168.

Voigt, C.C., Kelm, D.H., Bradley, B.J., and Ortmann, S. 2009. Dietary Analysis of Plant-visiting Bats. In Ecological and Behavioral Methods for the Study of Bats, 2nd ed. Edited by T.H.

Ward, A.L. 1970. Stomach content and fecal analysis. In Range and Wildlife Habitat Evaluation. US Forest Service Miscellaneous Publications, Washington, D.C. pp. 146-158.

Wilkinson, G.S., and Fleming, T.H. 1996. Migration and evolution of lesser long-nosed bats doi:10.1111/j.1365-294X.1996.tb00324.x.

Zeale, M.R.K., Butlin, R.K., Barker, G.L.A., Lees, D.C., and Jones, G. 2011. Taxon-specific PCR for DNA barcoding arthropod prey in bat faeces. Mol. Ecol. Resour. 11(2): 236-244. 


\section{Supplemental materials legends}

541 Figure S1. The diversity of plant taxa found for the three DNA regions used to conduct

542 metabarcoding analysis of guano $(\mathrm{G})$ and pollen-swab samples (S). Stacked bar graphs represent

543 the proportion of reads by plant taxon in each sample group.

545 Table S1. Information on primers used in the study. To enable sequencing on a Roche 454 GX

546 FLX, Forward primers were tagged on the 5' end with the 454 Adaptor A

547 (CGTATCGCCTCCCTCGCGCCATCAG). Reverse primers were tagged on the 5' end with the 548454 Adaptor B CTATGCGCCTTGCCAGCCCGCTCAG. For each primer, we ordered the same 549 primer but plus a group-specific MID.

550

551 Table S2. Number of sequencing reads and annotated sequences per sample and marker, 552 including the total, and mean in parentheses. 
557 Table 1. Sample collection information, including the type of sample, collection date, number of

558 samples collected per group, and the species represented.

\begin{tabular}{|c|c|c|c|c|c|c|c|}
\hline $\begin{array}{l}\text { Pooled } \\
\text { sample } \\
\text { Group } \\
\text { and } \\
\text { MID } \\
\end{array}$ & Sampling Location & Sampling Date(s) & $\begin{array}{l}\text { Sample } \\
\text { Type }\end{array}$ & $N$ & Species & $\begin{array}{l}\text { Visual } \\
\text { pollen } \\
\text { analysis? }\end{array}$ & $\begin{array}{l}\text { Produced } \\
\text { Plant } \\
\text { Sequences? }\end{array}$ \\
\hline 1 & Pyeatt Cave & SEP 10-11 2009 & & 30 & both & & \\
\hline 2 & Wren Bridge & SEP 09-12 2009 & Guano & 26 & both & Yes & Yes \\
\hline 3 & Wren Bridge & $\begin{array}{l}\text { AUG } 302010 \text { - } \\
\text { SEP } 032010\end{array}$ & Guano & 2 & both & & \\
\hline 4 & Wren Bridge & SEP 032010 & Guano & 32 & both & Yes & Yes \\
\hline 5 & Pyeatt Cave & SEP 042010 & Guano & 40 & both & Yes & Yes \\
\hline 6 & Arivaca & AUG 09-16 2010 & Swab & 6 & L. yerbabuenae & Yes & Yes \\
\hline 7 & Arivaca & AUG 10-16 2010 & Swab & 3 & C. mexicana & & Yes \\
\hline 8 & Bisbee & AUG 162010 & Swab & 3 & L. yerbabuenae & & Yes \\
\hline 9 & Wren Bridge & AUG 302010 & Swab & 11 & L. yerbabuenae & & Yes \\
\hline 10 & Ramsey Canyon & AUG 312010 & Swab & 2 & C. mexicana & & \\
\hline 11 & Ramsey Canyon & AUG 312010 & Swab & 7 & L. yerbabuenae & & Yes \\
\hline 12 & Nogales & SEP 012010 & Swab & 12 & L. yerbabuenae & Yes & Yes \\
\hline $\begin{array}{l}13 \\
14\end{array}$ & $\begin{array}{l}\text { Nogales } \\
\text { Arivaca }\end{array}$ & $\begin{array}{l}\text { SEP } 012010 \\
\text { SEP } 212010\end{array}$ & $\begin{array}{l}\text { Swab } \\
\text { Swab }\end{array}$ & $\begin{array}{l}4 \\
5\end{array}$ & $\begin{array}{l}\text { C. mexicana } \\
\text { L. yerbabuenae }\end{array}$ & Yes & \\
\hline $\begin{array}{l}15 \\
16 \\
17\end{array}$ & $\begin{array}{l}\text { Arivaca } \\
\text { Hubbard Residence } \\
\text { Manderscheid } \\
\text { Residence }\end{array}$ & $\begin{array}{l}\text { SEP } 212010 \\
\text { SEP } 242010 \\
\text { SEP } 292010\end{array}$ & $\begin{array}{l}\text { Swab } \\
\text { Swab } \\
\text { Swab }\end{array}$ & $\begin{array}{l}1 \\
1 \\
1\end{array}$ & $\begin{array}{l}\text { C. mexicana } \\
\text { L. yerbabuenae } \\
\text { L. yerbabuenae }\end{array}$ & & Yes \\
\hline 18 & Osbrink Residence & OCT 012010 & Swab & 1 & L. yerbabuenae & & \\
\hline 19 & $\begin{array}{l}\text { Pedrogrosa } \\
\text { Mountains }\end{array}$ & OCT 042010 & Swab & 1 & L. yerbabuenae & & \\
\hline 20 & Nogales & OCT 062010 & Swab & 13 & L. yerbabuenae & & Yes \\
\hline 21 & Nogales & OCT 062010 & Swab & 5 & C. mexicana & & Yes \\
\hline 22 & Arivaca & OCT 11-18 2010 & Swab & 14 & C. mexicana & & Yes \\
\hline 23 & Arivaca & OCT 122010 & Swab & 3 & L. yerbabuenae & Yes & \\
\hline 24 & Tucson & AUG 252011 & Swab & 6 & L. yerbabuenae & & Yes \\
\hline 25 & Green Valley & AUG 292011 & Swab & 2 & C. mexicana & & Yes \\
\hline 26 & Green Valley & AUG 292011 & Swab & 7 & L. yerbabuenae & & Yes \\
\hline $\begin{array}{l}27 \\
28\end{array}$ & $\begin{array}{l}\text { Vail } \\
\text { Vail }\end{array}$ & $\begin{array}{l}\text { SEP } 012011 \\
\text { SEP } 012011\end{array}$ & $\begin{array}{l}\text { Swab } \\
\text { Swab }\end{array}$ & $\begin{array}{l}2 \\
3\end{array}$ & $\begin{array}{l}\text { C. mexicana } \\
\text { L. yerbabuenae }\end{array}$ & & \\
\hline 29 & Tucson & SEP 062011 & Swab & 6 & L. yerbabuenae & & Yes \\
\hline 30 & Oro Valley & SEP 152011 & Swab & 6 & L. yerbabuenae & & $\begin{array}{l}\text { Yes } \\
\text { Yes }\end{array}$ \\
\hline
\end{tabular}




\begin{tabular}{|c|c|c|c|c|c|c|}
\hline 31 & Elfrida & AUG 232011 & Swab & 1 & L. yerbabuenae & \\
\hline 32 & Wilcox & AUG 312011 & Swab & 1 & L. yerbabuenae & \\
\hline 33 & Nogales & AUG 222011 & Swab & 1 & C. mexicana & \\
\hline 34 & Wilcox & AUG 082011 & Swab & 1 & L. yerbabuenae & \\
\hline 35 & Rio Rico & AUG 152011 & Swab & 1 & L. yerbabuenae & \\
\hline 36 & Arivaca & AUG 142011 & Swab & 2 & C. mexicana & \\
\hline 37 & Arivaca & AUG 142011 & Swab & 6 & L. yerbabuenae & \\
\hline 38 & Arivaca & SEP 052011 & Swab & 3 & C. mexicana & $\begin{array}{l}\text { Yes } \\
\text { Yes }\end{array}$ \\
\hline 39 & Arivaca & SEP 052011 & Swab & 3 & L. yerbabuenae & Yes \\
\hline 40 & Arivaca & OCT 032011 & Swab & 1 & C. mexicana & \\
\hline 41 & Arivaca & OCT 032011 & Swab & 4 & L. yerbabuenae & \\
\hline 42 & Arivaca & OCT 042011 & Swab & 2 & L. yerbabuenae & \\
\hline 43 & Pyeatt Cave & NOV 082011 & Swab & 1 & L. yerbabuenae & \\
\hline
\end{tabular}


Figure 1. Images showing sample collection techniques. A-D) Approach to collect guano samples, including: A) sheeting placed in a flyway in Pyeatt cave, B) Sheeting placed under wren bridge, C) collection of guano sample from sheeting, D) collection tube containing RNAlater, sample, and swab. E-F) Approach to collect pollen-swab samples, where E) Leptonycteris yerbabuenae, and F) Choeronycteris mexicana were captured and swabbed to remove pollen from their muzzles. Photo credits: A and B, Ronnie Sidner; C, E, and F, Eric Britzke; D, Joel Swift.

Figure 2. The diversity of plant taxa found through metabarcoding analysis of guano (A) and pollen-swab samples (B). Pie charts depict the number of total reads recovered for each plant taxon, with all samples of a type (i.e., guano or swab) combined (information for slices $>1 \%$ combined into the category "other angiosperms"). (C) Stacked bar graphs represent the proportion of reads by plant taxon in each pooled sample. 


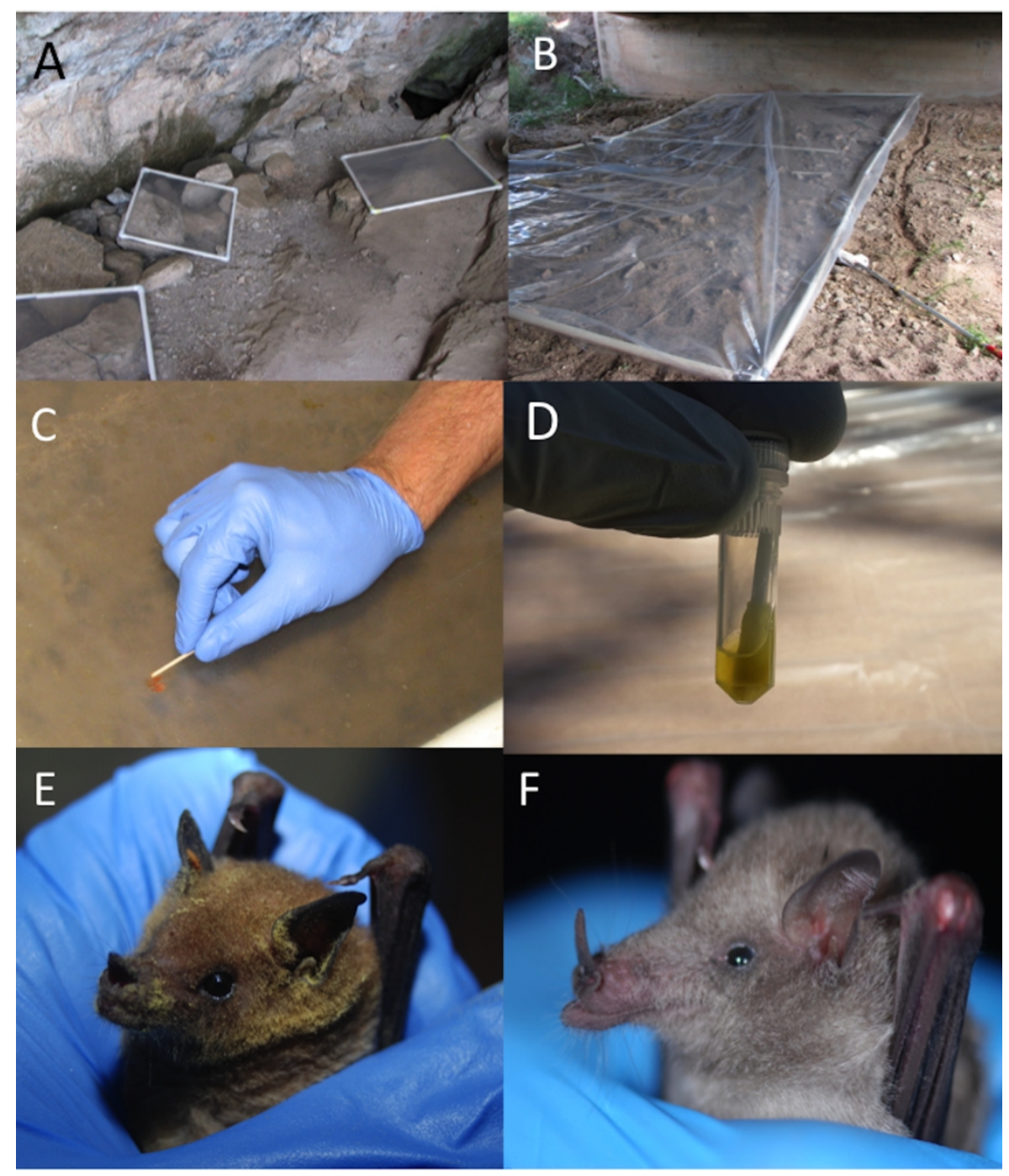

Fig. 1

$254 \times 338 \mathrm{~mm}(300 \times 300 \mathrm{DPI})$ 

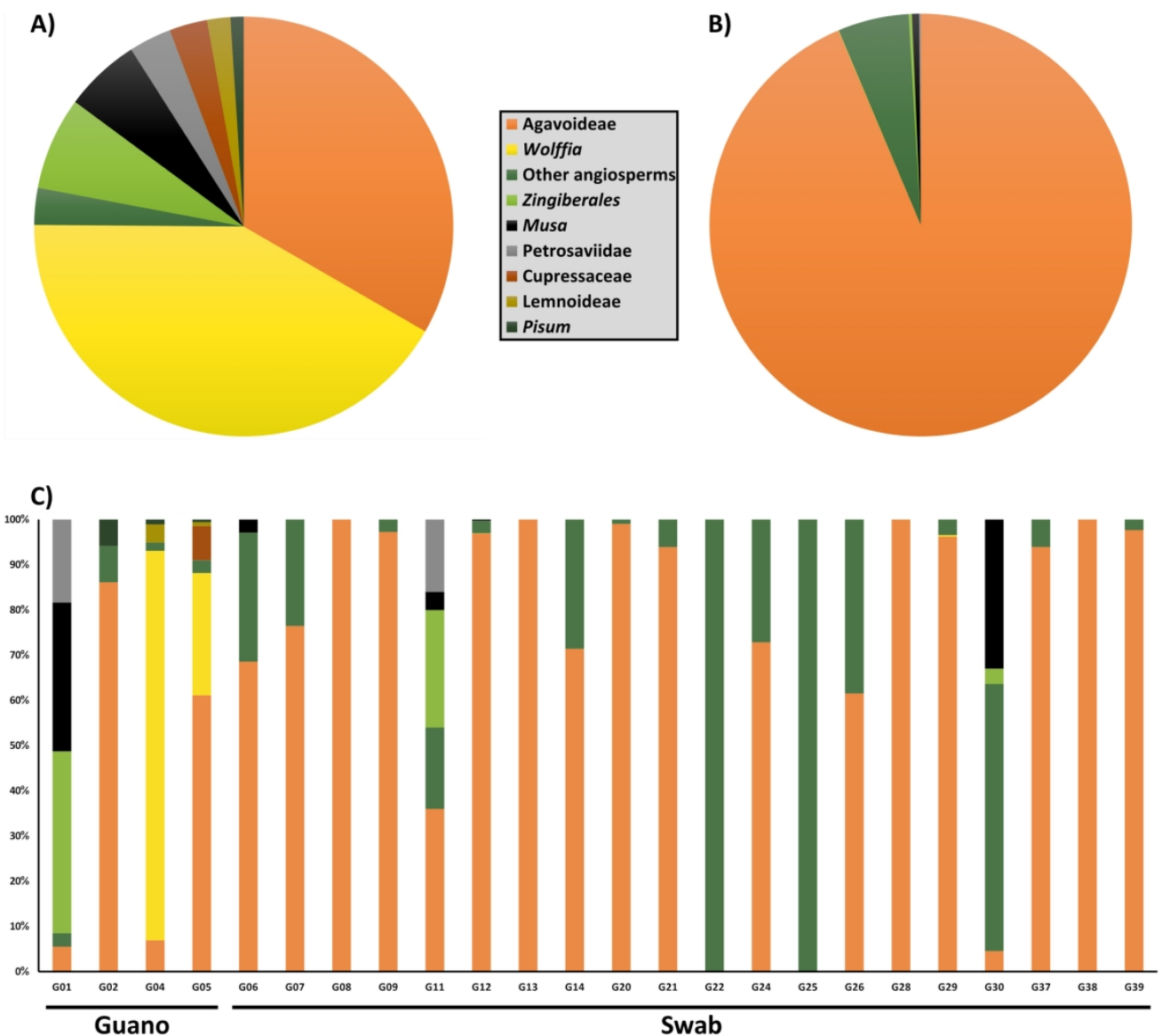

Figure 2.

$177 \times 162 \mathrm{~mm}(300 \times 300$ DPI $)$ 